\title{
Design and Evaluation of Regioselective Drug Delivery System By Using Dipyridamole Deug As Model
}

\author{
Faheem Unnisa Begum*, Maimona Farheen, Asfia Kauser, Ayesha Haseena, \\ Sumaiya Sultana, Zehra Afreen, Zeenath Anjum \\ *Assistant Professor, Shadan Women's College of Pharmacy, Khiartabad, Hyderabad Department of \\ Pharmaceutics
}

\begin{abstract}
In the present research work the gastro retentive floating matrix formulation of Dipyridamole by using various hydrophilic polymers. Initially analytical method development was done for the drug molecule. Absorption maxima was determined based on that calibration curve was developed by using different concentrations. Gas generating agent sodium bicarbonate concentration was optimized. Then the formulation was developed by using different concentrations of polymers of various natural polymers. The formulation blend was subjected to various preformulation studies, flow properties and all the formulations were found to be good indicating that the powder blend has good flow properties. Among all the formulations the formulations prepared by using Xanthum gum were unable to produce desired drug release, they were unable to retard drug release up to 12 hours. The formulations prepared with HPMC K15 M retarded the drug release up to 12 hours in the concentration of $200 \mathrm{mg}$ (F8).The formulations prepared with Guar gum were also retarded the drug release for more than 12 hours. Hence they were not considered. The optimized formulation dissolution data was subjected to release kinetics, from the release kinetics data it was evident that the formulation F8 followed Zero mechanism of drug release.
\end{abstract}

Keywords: Dipyridamole, Guar gum, Xanthum gum ,HPMC K15 M and Floating tablets.

\section{Introduction}

\subsection{INTRODUCTION ON FLOATING DRUG DELIVERY SYSTEMS}

Buoyant/ Floating Systems: Floating Drug Delivery Systems (FDDS) have a bulk density lower than gastric fluids and thus remain buoyant in the stomach for a prolonged period of time, without affecting the gastric emptying rate. While the system is floating on the gastric contents, the drug is released slowly at a desired rate from the system. After the release of the drug, the residual system is emptied from the stomach. This results in an increase in the GRT and a better control of fluctuations in the plasma drug concentrations.

Based on the mechanism of buoyancy, two distinctly different technologies have been utilized in development of FDDS which are:Effervescent System, andNon- Effervescent System.

EFFERVESCENT SYSTEM:-Effervescent systems include use of gas generating agents, carbonates (ex. Sodium bicarbonate) and other organic acid (e.g. citric acid and tartaric acid) present in the formulation to produce carbon dioxide $\left(\mathrm{CO}_{2}\right)$ gas, thus reducing the density of the system and making it float on the gastric fluid. An alternative is the incorporation of matrix containing portion of liquid, which produce gas that evaporates at body temperature.

These effervescent systems further classified into two types.

- Gas Generating systems

- Volatile Liquid/Vacuum Containing Systems.

NON-EFFERVESCENT SYSTEMS: The Non-effervescent FDDS based on mechanism of swelling of polymer or bioadhesion to mucosal layer in GI tract. The most commonly used excipients in non-effervescent FDDS are gel forming or highly swellable cellulose type hydrocolloids, polysaccharides and matrix forming material such as Polycarbonate, Polyacrylate, Polymethacrylate, polystyrene as well as bioadhesive polymer such as Chitosan and Carbopol. The various types of this system are as:

Single Layer Floating Tablets: They are formulated by intimate mixing of drug with a gel-forming hydrocolloid, which swells in contact with gastric fluid and maintain bulk density of less than unity.

Bilayer Floating Tablets: A bilayer tablet contain two layer one immediate release layer which release initial dose from system while the another sustained release layer absorbs gastric fluid, forming an impermeable colloidal gel barrier on its surface, and maintain a bulk density of less than unity and thereby it remains buoyant in the stomach.

Alginate Beads: Multi unit floating dosage forms were developed from freeze-dried calcium alginate. Spherical beads of approximately $2.5 \mathrm{~mm}$ diameter can be prepared by dropping a sodium alginate solution into aqueous 
solution of calcium chloride, causing precipitation of calcium alginate leading to formation of porous system, which can maintain a floating force for over 12 hours.

Hollow Microspheres: Hollow microspheres (micro balloons), loaded with drug in their outer polymer shells were prepared by a novel emulsion-solvent diffusion method. The ethanol: dichloromethane solution of the drug and an enteric acrylic polymer was poured into an agitated aqueous solution of PVA that was thermally controlled at $40^{\circ} \mathrm{C}$. The gas phase generated in dispersed polymer droplet by evaporation of dichloromethane formed an internal cavity in microsphere of polymer with drug. The micro balloons floated continuously over the surface of acidic dissolution media containing surfactant for more than 12 hours in vitro.

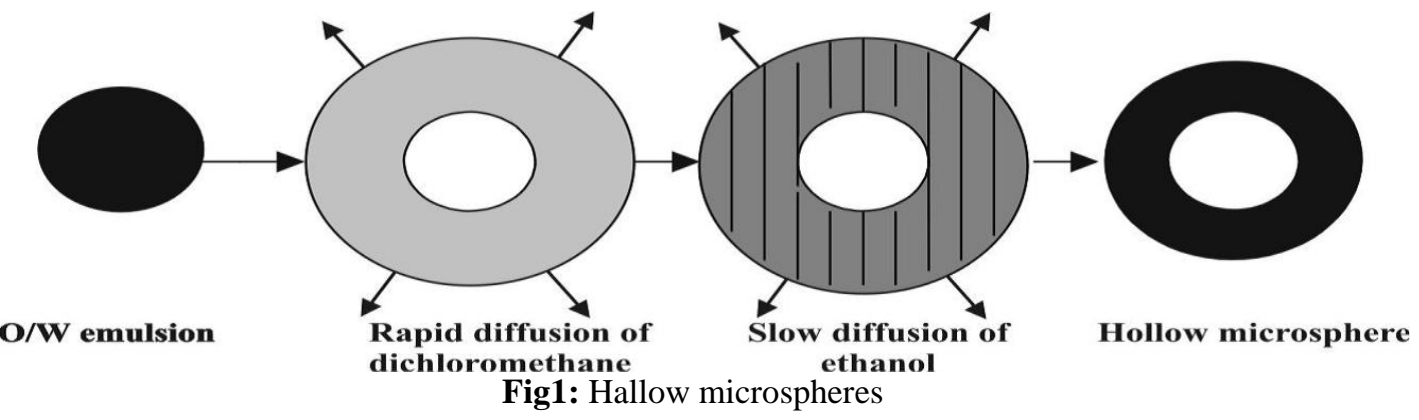

Advantages of FDDS:

- Improved drug absorption, because of increased GRT and more time spent by the dosage form at its absorption site.

- $\quad$ Controlled delivery of drugs.

3. Minimizing the mucosal irritation due to drugs

- Treatment of gastrointestinal disorders such as gastro-esophageal reflux.

\section{Disadvantages of FDDS:}

- Gastric retention is influenced by many factors such as gastric motility, $\mathrm{pH}$ and presence of food. These factors are never constant and hence the buoyancy cannot be predicted.

- Drugs that cause irritation and lesion to gastric mucosa are not suitable to be formulated as floating drug delivery systems.

\section{Materials and Methods}

\begin{tabular}{|l|l|}
\hline S.no & Materials \\
\hline 1. & Dipyridamole \\
\hline 2. & Guar Gum \\
\hline 3. & Xanthum Gum \\
\hline 4. & HPMC K15M \\
\hline 5. & Sodium bicarbonate \\
\hline 6. & Magnesium stearate \\
\hline 7. & Micro crystalline cellulose \\
\hline 8. & Talc \\
\hline
\end{tabular}

\section{Analytical method development:}

\section{- Determination of absorption maxima:}

A solution containing the concentration $10 \mu \mathrm{g} / \mathrm{ml}$ drug was prepared in $0.1 \mathrm{~N} \mathrm{HCl} \mathrm{UV} \mathrm{spectrum} \mathrm{was} \mathrm{taken} \mathrm{using}$ Double beam UV/VIS spectrophotometer. The solution was scanned in the range of $200-400$.

\section{2,1Drug - Excipient compatibility studies:}

Formulation development of Tablets:

All the formulations were prepared by direct compression. The compression of different formulations is given in Table .The tablets were prepared as per the procedure given below and aim is to prolong the release of Dipyridamole. Total weight of the tablet was considered as $600 \mathrm{mg}$.

\section{Procedure:}

- Dipyridamole and all other ingredients were individually passed through sieve no 60 .

- All the ingredients were mixed thoroughly by triturating up to $15 \mathrm{~min}$.

- The powder mixture was lubricated with talc.

- The tablets were prepared by using direct compression method. 
Design And Evaluation Of Regioselective Drug Delivery System By Using Dipyridamole Deug As ..

Optimization of Sodium bicarbonate concentration:

Sodium bicarbonate was employed as effervescent gas generating agent. It helps the formulation to float. Various concentrations of sodium bicarbonate were employed; floating lag time and floating duration were observed. Based on the concentration of sodium bicarbonate was finalized and preceded for further formulations.

\begin{tabular}{|l|l|l|l|l|}
\hline S.No & Excipient Name & EF1 & EF2 & EF3 \\
\hline 1 & Dipyridamole & 300 & 300 & 300 \\
\hline 2 & $\mathrm{HPMC} \mathrm{K15} \mathrm{M}_{2}$ & 150 & 150 & 150 \\
\hline 4 & $\mathrm{NaHCO}_{3}$ & 75 & 90 & 105 \\
\hline 5 & Mg.Stearate & 6 & 6 & 6 \\
\hline 5 & Talc & 6 & 6 & 6 \\
\hline 7 & MCC pH 102 & Q.S & Q.S & Q.S \\
\hline & Total weight & 600 & 600 & 600 \\
\hline
\end{tabular}

All the quantities were in $\mathrm{mg}$.

Table1 : Optimization sodium bicarbonate concentration

\begin{tabular}{|c|c|c|c|c|c|c|c|c|}
\hline $\begin{array}{c}\text { Formulation } \\
\text { No. }\end{array}$ & Dipyrridamole & $\begin{array}{c}\text { Xanthum } \\
\text { gum }\end{array}$ & $\begin{array}{c}\text { HPMC } \\
\text { K15 M }\end{array}$ & $\begin{array}{c}\text { Guar } \\
\text { gum }\end{array}$ & NaHCO $_{3}$ & $\begin{array}{c}\text { Mag. } \\
\text { Stearate }\end{array}$ & $\begin{array}{c}\text { Talc } \\
\text { MCC pH } \\
\mathbf{1 0 2}\end{array}$ \\
\hline F1 & 300 & 50 & & & 90 & 6 & 6 & QS \\
\hline F2 & 300 & 100 & & & 90 & 6 & 6 & QS \\
\hline F3 & 300 & 150 & & & 90 & 6 & 6 & QS \\
\hline F4 & 300 & 200 & & & 90 & 6 & 6 & QS \\
\hline F5 & 300 & & 50 & & 90 & 6 & 6 & QS \\
\hline F6 & 300 & & 100 & & 90 & 6 & 6 & QS \\
\hline F7 & 300 & & 150 & & 90 & 6 & 6 & QS \\
\hline F8 & 300 & & 200 & & 90 & 6 & 6 & QS \\
\hline F9 & 300 & & & 50 & 90 & 6 & 6 & QS \\
\hline F10 & 300 & & & 100 & 90 & 6 & 6 & QS \\
\hline F11 & 300 & & & 150 & 90 & 6 & 6 & QS \\
\hline F12 & 300 & & & 200 & 90 & 6 & 6 & QS \\
\hline
\end{tabular}

All the quantities were in $\mathrm{mg}$, Total weight is $600 \mathrm{mg}$.

Table 2 : Formulation composition for floating tablets

\subsection{Evaluation of post compression parameters for prepared Tablets}

The designed compression tablets were studied for their physicochemical properties like weight variation, hardness, thickness, friability and drug content. The optimised tablets were subjected to In vitro buoyancy studies, In vitro drug release studies and application of release rate kinetics to dissolution data ( Zero order, First order, Higuchi release model, Korsmeyer and Peppas release model, and Hixson-Crowell release model)

\section{Results and Discussions}

The present study was aimed to developing gastro retentive floating tablets of Dipyridamole using various natural polymers. All the formulations were evaluated for physicochemical properties and invitro drug release studies.

\subsection{Analytical Method}

Graph of Dipyridamole was taken in Simulated Gastric fluid (pH 1.2) at $288 \mathrm{~nm}$.

\begin{tabular}{|c|c|}
\hline Conc $[\boldsymbol{\mu g} / \mathbf{l}]$ & Abs \\
\hline 2 & 0.131 \\
\hline 4 & 0.252 \\
\hline 6 & 0.367 \\
\hline 8 & 0.479 \\
\hline 10 & 0.619 \\
\hline
\end{tabular}

Table 3: Observations for graph of Dipyridamolein $0.1 \mathrm{~N} \mathrm{HCl}(288 \mathrm{~nm})$ 
Figure 2: Standard graph of Dipyrridamole in $0.1 \mathrm{~N} \mathrm{HCl}$

\subsection{Drug - Excipient compatability studies}

Fourier Transform-Infrared Spectroscopy:

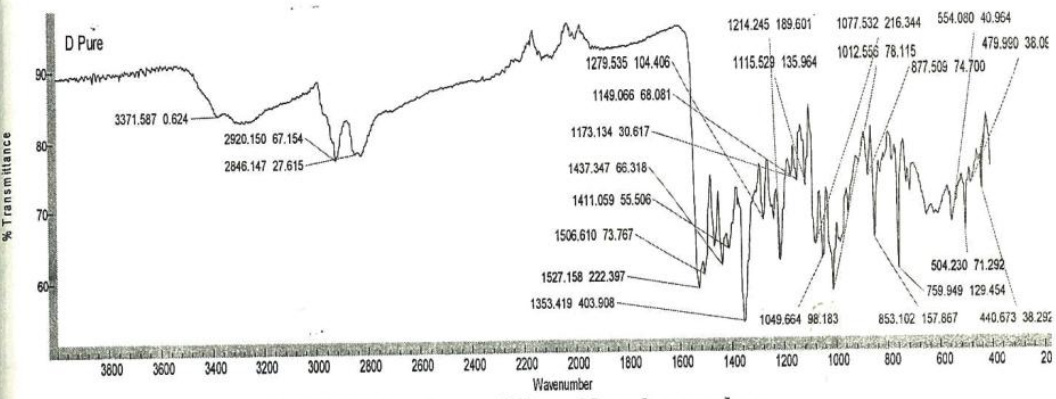

Figure 7.2: FT-TR Spectrum of Dipyrridamole pure drug.

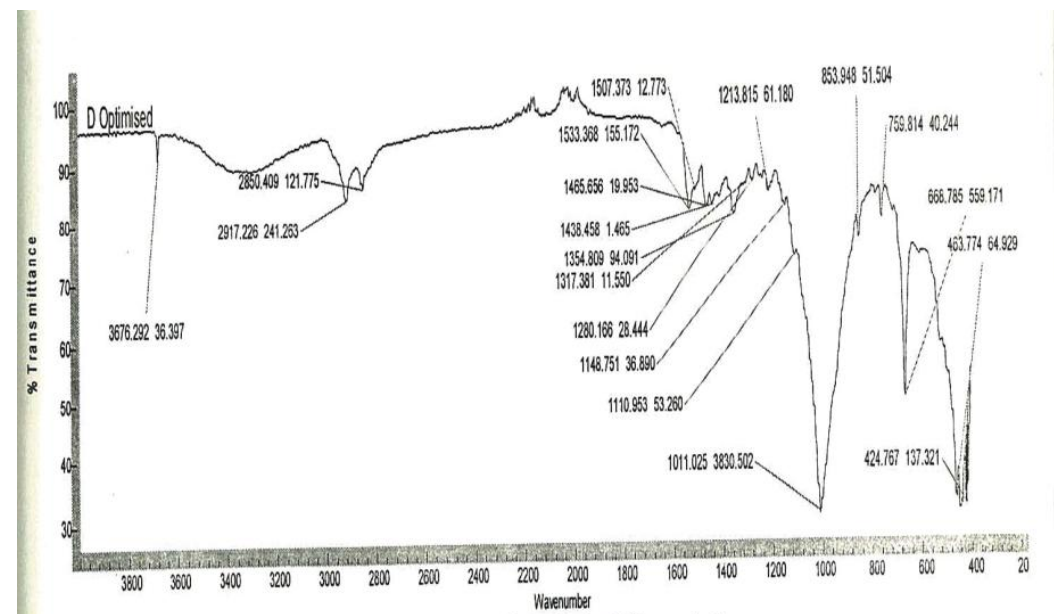

Figure 7.3: FT-IR Spectrum of Optimised Formulation

3.4. Preformulation parameters of powder blend

\begin{tabular}{|c|c|l|l|l|l|}
\hline Formulation Code & Angle of Repose & $\begin{array}{c}\text { Bulk density } \\
(\mathbf{g m} / \mathbf{m l})\end{array}$ & $\begin{array}{c}\text { Tapped density } \\
(\mathbf{g m} / \mathbf{m} \mathbf{)})\end{array}$ & Carr's index (\%) & Hausner's Ratio \\
\hline F1 & 26.01 & 0.45 & 0.54 & 16.6 & 1.2 \\
\hline F2 & 24.8 & 0.50 & 0.61 & 18.03 & 1.22 \\
\hline F3 & 22.74 & 0.47 & 0.58 & 18.96 & 1.23 \\
\hline F4 & 25.33 & 0.48 & 0.59 & 18.64 & 1.22 \\
\hline F5 F6 & 26.24 & 0.51 & 0.62 & 17.74 & 1.21 \\
\hline F7 & 26.12 & 0.50 & 0.61 & 18.03 & 1.22 \\
\hline F8 & 27.08 & 0.49 & 0.60 & 18.33 & 1.22 \\
\hline F9 & 25.12 & 0.48 & 0.58 & 17.24 & 1.20 \\
\hline F10 & 25.45 & 0.46 & 0.57 & 16.28 & 1.23 \\
\hline F11 & 27.51 & 0.45 & 0.54 & 18.03 & 1.2 \\
\hline
\end{tabular}

Table 4: Pre-formulation parameters of blend

Tablet powder blend was subjected to various pre-formulation parameters. The angle of repose values indicates that the powder blend has good flow properties. The bulk density of all the formulations was found to be in the range of 0.45 to $0.51(\mathrm{gm} / \mathrm{cm} 3)$ showing that the powder has good flow properties. The tapped density of all the formulations was found to be in the range of 0.54 to 0.62 showing the powder has good flow properties. The compressibility index of all the formulations was found to be ranging from 15 to 18 which show that the powder has good flow properties. All the formulations has shown the hausner ratio ranging less than 1.25 indicating the powder has good flow properties. 
Design And Evaluation Of Regioselective Drug Delivery System By Using Dipyridamole Deug As ..

\subsection{Optimization of sodium bicarbonate concentration:}

Three formulations were prepared with varying concentrations of sodium bicarbonate. The formulation containing sodium bicarbonate in $90 \mathrm{mg}$ concentration showed less floating lag time of 4 min and the tablet was in floating condition for more than 12 hours.

\subsection{Quality Control Parameters For tablets:}

Tablet quality control tests such as weight variation, hardness, and friability, thickness, and drug release studies in different media were performed on the tablets.

\begin{tabular}{|c|c|c|c|c|c|c|}
\hline $\begin{array}{c}\text { Formulation } \\
\text { code }\end{array}$ & $\begin{array}{c}\text { Weight } \\
\text { variation(mg) }\end{array}$ & $\begin{array}{c}\text { Hardness } \\
(\mathbf{k g} / \mathbf{c m})\end{array}$ & $\begin{array}{c}\text { Friability } \\
(\boldsymbol{\%} \mathbf{l o s s})\end{array}$ & $\begin{array}{c}\text { Thickness } \\
(\mathbf{m m})\end{array}$ & $\begin{array}{c}\text { Drug content } \\
(\boldsymbol{\%})\end{array}$ & $\begin{array}{c}\text { Flaoting } \\
\text { lag time } \\
(\mathbf{m i n})\end{array}$ \\
\hline F1 & 612.5 & 4.5 & 0.52 & 4.8 & 99.76 & 4.0 \\
\hline F2 & 605.4 & 4.2 & 0.54 & 4.9 & 99.45 & 4.2 \\
\hline F3 & 598.6 & 4.4 & 0.51 & 4.9 & 98.34 & 4.5 \\
\hline F4 & 610.6 & 4.5 & 0.55 & 4.9 & 99.87 & 4.1 \\
\hline F5 & 609.4 & 4.4 & 0.56 & 4.7 & 99.14 & 4.0 \\
\hline F6 & 610.7 & 4.2 & 0.45 & 4.5 & 98.56 & 4.4 \\
\hline F7 & 602.3 & 4.1 & 0.51 & 4.4 & 98.42 & 4.5 \\
\hline F8 & 601.2 & 4.3 & 0.49 & 4.7 & 99.65 & 4.6 \\
\hline F9 & 598.3 & 4.5 & 0.55 & 4.6 & 99.12 & 4.7 \\
\hline F10 & 600.5 & 4.5 & 0.56 & 4.6 & 98.56 & 4.5 \\
\hline F11 & 602.5 & 4.5 & 0.58 & 4.8 & 99.45 & 4.3 \\
\hline F12 & 600.6 & 4.5 & 0.63 & 4.7 & 98.54 & 4.4 \\
\hline
\end{tabular}

Table 5. Invitro quality control parameters for tablets

All the parameters such as weight variation, friability, hardness, thickness and drug content were found to be within limits.

3.7. In-Vitro Drug Release Studies

\begin{tabular}{|c|c|c|c|c|}
\hline \multirow{2}{*}{$\begin{array}{c}\text { TIME } \\
\text { (hr) }\end{array}$} & \multicolumn{4}{|c|}{ CUMULATIVE PERCENT DRUG DISSOLVED } \\
\cline { 2 - 5 } $\mathbf{0 . 5}$ & $\mathbf{F 1}$ & $\mathbf{F 2}$ & $\mathbf{F 3}$ & F34 \\
$\mathbf{1}$ & 21.73 & 18.52 & 15.43 & 12.53 \\
$\mathbf{2}$ & 59.23 & 37.47 & 28.31 & 25.97 \\
\hline $\mathbf{3}$ & 84.9 & 59.93 & 40.36 & 34.89 \\
\hline $\mathbf{4}$ & 99.873 & 65.85 & 58.48 & 45.76 \\
$\mathbf{5}$ & & 77.54 & 70.21 & 56.38 \\
$\mathbf{6}$ & & 99.55 & 82.54 & 64.2 \\
\hline $\mathbf{7}$ & & & 96.64 & 69.06 \\
\hline $\mathbf{8}$ & & & & 77.52 \\
\hline $\mathbf{9}$ & & & & 87.88 \\
\hline
\end{tabular}

Table 6: Dissolution Data of Dipyrridamole Tablets Prepared With Xanthum gum In Different Concentrations

Fig 3: Dissolution profile of Dipyrridamole floating tablets (F1, F2, F3,F4 formulations).

\begin{tabular}{|c|c|c|c|c|}
\hline \multirow{2}{*}{$\begin{array}{c}\text { TIME } \\
(\mathbf{h r})\end{array}$} & \multicolumn{3}{|c|}{ CUMULATIVE PERCENT DRUG DISSOLVED } \\
\cline { 2 - 5 } & $\mathbf{F 5}$ & $\mathbf{F 6}$ & $\mathbf{F 7}$ & F8 \\
\hline $\mathbf{0 . 5}$ & 23.45 & 20.42 & 17.48 & 14.62 \\
\hline $\mathbf{1}$ & 36.26 & 29.73 & 25.37 & 19.86 \\
\hline $\mathbf{3}$ & 52.16 & 35.63 & 32.28 & 26.35 \\
\hline $\mathbf{4}$ & 70.01 & 40.04 & 38.21 & 31.45 \\
\hline $\mathbf{5}$ & 87.26 & 49.25 & 44.38 & 39.80 \\
\hline $\mathbf{6}$ & 96.10 & 56.33 & 50.83 & 44.25 \\
\hline $\mathbf{7}$ & & 62.41 & 58.32 & 52.24 \\
\hline $\mathbf{8}$ & & 70.84 & 64.39 & 58.73 \\
\hline $\mathbf{9}$ & & 88.80 & 71.71 & 64.34 \\
\hline $\mathbf{1 0}$ & & 97.58 & 85.46 & 72.52 \\
\hline $\mathbf{1 2}$ & & & 97.38 & 80.17 \\
\hline
\end{tabular}

Table 7: Dissolution Data of Dipyrridamole Tablets Prepared With HPMC K15M In Different Concentrations

Fig4: Dissolution profile of Dipyrridamole floating tablets (F5, F6, F7,F8 formulations). 
Design And Evaluation Of Regioselective Drug Delivery System By Using Dipyridamole Deug As ..

\begin{tabular}{|c|c|c|c|c|}
\hline \multirow{2}{*}{$\begin{array}{l}\text { TIME } \\
\text { (hr) }\end{array}$} & \multicolumn{4}{|c|}{ CUMULATIVE PERCENT DRUG DISSOLVED } \\
\hline & F9 & F10 & F11 & F12 \\
\hline 0.5 & 17.81 & 14.89 & 12.74 & 10.21 \\
\hline 1 & 26.02 & 20.04 & 18.27 & 14.87 \\
\hline 2 & 32.70 & 26.43 & 25.48 & 22.19 \\
\hline 3 & 40.32 & 35.65 & 30.28 & 28.66 \\
\hline 4 & 48.25 & 44.18 & 38.47 & 33.32 \\
\hline 5 & 56.28 & 51.81 & 44.37 & 40.06 \\
\hline 6 & 64.92 & 53.89 & 49.29 & 47.13 \\
\hline 7 & 75.08 & 60.53 & 55.38 & 53.63 \\
\hline 8 & 80.44 & 79.43 & 61.25 & 58.71 \\
\hline 9 & 97.22 & 76.83 & 68.47 & 63.34 \\
\hline 10 & & 86.98 & 74.21 & 69.27 \\
\hline 11 & & 96.54 & 80.43 & 72.86 \\
\hline 12 & & & 89.34 & 80.97 \\
\hline
\end{tabular}

Table 8: Dissolution Data of Dipyrridamole Tablets Prepared With Guar Gum In Different Concentrations

\section{Fig 5: Dissolution profile of Dipyrridamole floating tablets (F9, F10, F11,F12 formulations)}

From the dissolution data it was evident that the formulations prepared with Xanthum gum as polymer were unable to retard the drug release up to desired time period i.e., 12 hours. Whereas the formulations prepared with HPMC K15M retarded the drug release in the concentration of $200 \mathrm{mg}$ showed required release pattern i.e., retarded the drug release up to 12 hours and showed maximum of $97.33 \%$ in 12 hours (Formulation F6) with good floating lag time and floating buoyancy time. The formulations prepared with Guar gum showed more retardation even after 12 hours they were not shown total drug release. Hence they were not considered.

\section{Application of Release Rate Kinetics to Dissolution Data:}

Various models were tested for explaining the kinetics of drug release. To analyze the mechanism of the drug release rate kinetics of the dosage form, the obtained data were fitted into zero-order, first order, Higuchi and Korsmeyer-Peppas release model.

\begin{tabular}{|c|c|c|c|c|c|c|c|c|}
\hline $\begin{array}{c}\text { CUMULATIV } \\
\text { E (\%) } \\
\text { RELEASE Q }\end{array}$ & $\begin{array}{c}\text { TIME } \\
(\mathbf{T})\end{array}$ & $\begin{array}{l}\text { ROOT } \\
(\mathbf{T})\end{array}$ & $\begin{array}{c}\text { LOG( \%) } \\
\text { RELEASE }\end{array}$ & $\begin{array}{l}\text { LOG } \\
(\mathrm{T})\end{array}$ & $\begin{array}{c}\text { LOG } \\
(\%) \\
\text { REMAIN }\end{array}$ & $\begin{array}{c}\text { RELEASE } \\
\text { RATE } \\
\text { (CUMULATIVE \% } \\
\text { RELEASE / t) }\end{array}$ & $\begin{array}{l}\text { 1/CUM\% } \\
\text { RELEASE }\end{array}$ & $\begin{array}{c}\text { PEPPAS } \\
\log Q / 100\end{array}$ \\
\hline 0 & 0 & 0 & & & 2.000 & & & \\
\hline 14.62 & 0.5 & 0.707 & 1.165 & -0.301 & 1.931 & 29.240 & 0.0684 & -0.835 \\
\hline 19.86 & 1 & 1.000 & 1.298 & 0.000 & 1.904 & 19.860 & 0.0504 & -0.702 \\
\hline 26.35 & 2 & 1.414 & 1.421 & 0.301 & 1.867 & 13.175 & 0.0380 & -0.579 \\
\hline 31.45 & 3 & 1.732 & 1.498 & 0.477 & 1.836 & 10.483 & 0.0318 & -0.502 \\
\hline 39.8 & 4 & 2.000 & 1.600 & 0.602 & 1.780 & 9.950 & 0.0251 & -0.400 \\
\hline 44.25 & 5 & 2.236 & 1.646 & 0.699 & 1.746 & 8.850 & 0.0226 & -0.354 \\
\hline 52.24 & 6 & 2.449 & 1.718 & 0.778 & 1.679 & 8.707 & 0.0191 & -0.282 \\
\hline 58.73 & 7 & 2.646 & 1.769 & 0.845 & 1.616 & 8.390 & 0.0170 & -0.231 \\
\hline 64.34 & 8 & 2.828 & 1.808 & 0.903 & 1.552 & 8.043 & 0.0155 & -0.192 \\
\hline 72.52 & 9 & 3.000 & 1.860 & 0.954 & 1.439 & 8.058 & 0.0138 & -0.140 \\
\hline 80.17 & 10 & 3.162 & 1.904 & 1.000 & 1.297 & 8.017 & 0.0125 & -0.096 \\
\hline 89.75 & 11 & 3.317 & 1.953 & 1.041 & 1.011 & 8.159 & 0.0111 & -0.047 \\
\hline 97.33 & 12 & 3.464 & 1.988 & 1.079 & 0.427 & 8.111 & 0.0103 & -0.012 \\
\hline
\end{tabular}

Table 9: Release kinetics data for optimised formulation (F6)

Fig 6 : Zero order release kinetics graph

Fig 7 : Higuchi release kinetics graph

Fig 8: Kars mayer peppas graph

Fig 9: First order release kinetics graph

From the above graphs it was evident that the formulation 86 was followed Zero order release mechanism.

\section{Conclusion}

In the present research work the gastro retentive floating matrix formulation of Dipyrridamole by using various hydrophilic polymers. Initially analytical method development was done for the drug molecule. Absorption maxima was determined based on that calibration curve was developed by using different concentrations. Gas generating agent sodium bicarbonate concentration was optimized. Then the formulation was developed by using different concentrations of polymers of various natural polymers. The formulation blend was subjected to various preformualation studies, flow properties and all the formulations were found to be good 
indicating that the powder blend has good flow properties. Among all the formulations the formulations prepared by using Xanthum gum were unable to produce desired drug release; they were unable to retard drug release up to 12 hours. The formulations prepared with HPMC K15 M retarded the drug release up to 12 hours in the concentration of $200 \mathrm{mg}$ (F8). The formulations prepared with Guar gum were also retarded the drug release for more than 12 hours. Hence they were not considered. The optimized formulation dissolution data was subjected to release kinetics, from the release kinetics data it was evident that the formulation followed Zero order mechanism of drug release.

\section{Bibliography}

[1]. Leon Lachman, Herbert A. Liberman, the Theory and Practice of Industrial Pharmacy: P.293-302.

[2]. Robinson Jr, Lee V.H.L, Controlled drug delivery: Fundamentals and Applications, 2nd edn. Marcel Dekker, New york: (1978) P.2436.

[3]. Brahmankar D.M, Jaiswal S.B, Biopharmaceutics and Pharmacokinetics a treatise, 1st ed. Vallabh prakashan; New Delhi: (1995) P.64-70.

[4]. Chein Y.W, Novel Drug Delivery Systems, 2nd ed.: Marcel Dekker; New York: (1992) P.4-56.

[5]. Ansel, Pharmaceutical Dosage form and Drug Delivery System, Lipincott, 7th edition: P. 553.

[6]. Gennaro R.A. Remington,The Science and Practice of Pharmacy., 20th ed. New york : Lippincott Williams: (2000) P.1045.

[7]. Banker G.S, Rhodes C.T, Modern Pharmaceutics. 3rd ed. Marcel Dekker, New York: (1996) P.678-721.

[8]. Vyas S.P, Khar R.K, Controlled Drug Delivery: Concepts and Advances, 1st ed. Vallabh prakashan, New Delhi: (2002) P.345-376.

[9]. P.G.Yeole, Floating Drug Delivery System: Need and Development, Ind. J. Pharm Sci., (2005): 67(3); $265-272$.

[10]. Shweta Arora, Floating Drug Delivery: A Review, AAPS Pharmscitech., (2005): 47(11); P.268-272.

[11]. Libo Yang, A New Intragastric Delivery System for the Treatment of H.Pylori associated with gastric ulcers, Elsevier J. of controlled release., Apr(1999): 34 (5); P. 215-222.

[12]. Ross and Wilson, Anatomy Physiology and Health Education. 9th ed. Churchil Livingston, P. $295-311$.

[13]. Wilson K.R.W, Waugh A. Anatomy and physiology in Health and Illness, 9th ed. Churchill Livingstone: London: (1996). P. 342-345.

[14]. Garima Chawla, Gupta, Pharmaceutical technology, July (2003): 23(9); P.39-48.

[15]. Desai S, Bolton S. A Floating Controlled Release System: In-vitro and In-vivo evaluation, J. Pharm. Res., (1993): 10; P.1321-1325.

[16]. Garg S, Sharma S. Gastroretentive Drug Delivery Systems, Pharmatech, (2003): P.160-164.

[17]. Dr.Jose, Khalid Shah, Gastroretentive Drug Delivery System, Business brief, Pharmtech., (2003) P. $165-173$.

[18]. Deshpande A.A, Shah N.H, Rhodes C.T, Development of a Novel Controlled Release System for Gastric Retention, J. Pharm. Res., (1997): 14(6); P. 815-819.

[19]. Garima Chawla- A means to address regional variability in intestinal drug absorption: Pharmtech., (2003) P.234-238

[20]. David S.S. The effect of density on the gastric emptying on single and multiple unit dosage forms. J. Pharm Res., (1986): 3; P.208213 